\title{
26. SURVEY AT SITE 344, RIFT MOUNTAINS EAST OF KNIPOVICH RIFT
}

\author{
M. Talwani, Lamont-Doherty Geological Observatory of Columbia University, \\ Palisades, New York
}

\begin{abstract}
A site survey was made on Vema Cruise 30 in the area of the Knipovich Rift to locate a suitable site for drilling on Leg 38. Continuous measurements of depth, gravity, and magnetics as well as single-channel seismic reflection profiling were carried out. Track of Vema is indicated by dotted lines in Figure 1. The bathymetric map in Figure 1 clearly shows the position of the Knipovich Rift which at its deepest point is slightly over 3400 meters. The rift valley is strikingly linear and has a north-south strike. Several high peaks exist on either side of the rift valley. Some of the peaks reach depths under 1500 meters. To the east sediment cover increases and basement east of $90^{\circ} \mathrm{E}$ is completely buried under sediment cover.

The magnetic pattern is shown by plotting anomalies along track in Figure 2. The three northern tracks across the rift valley seem to be associated with large positive magnetic anomalies, though the three southern tracks, crossing the rift valley, seem to be associated
\end{abstract}

with much smaller anomalies. Although north-south lineations might be detected in the magnetics, the pattern is not too convincing.

In Figure 3, A-B and C-D are two single-channel seismic reflection profiles. In both cases the rift mountains to the east of the rift valley are clearly expressed in the topography. But farther east, the basement relief is buried under the sediments. There also appears to be some sediment in the rift valley.

At the location of Site 344 we see that between the presumably stratified turbidite layering and the basement lie transparent sediments. Obtaining samples of basement as well as of transparent sediments was an objective at Site 344.

Support for this work came from Contracts N0001467-A-0108-0004 and N00014-75-C-0210 with the U.S. Office of Naval Research and from Grants GA1434, GP5392, GA17731, GA27281, and DES71-00214-A07 from the National Science Foundation. 


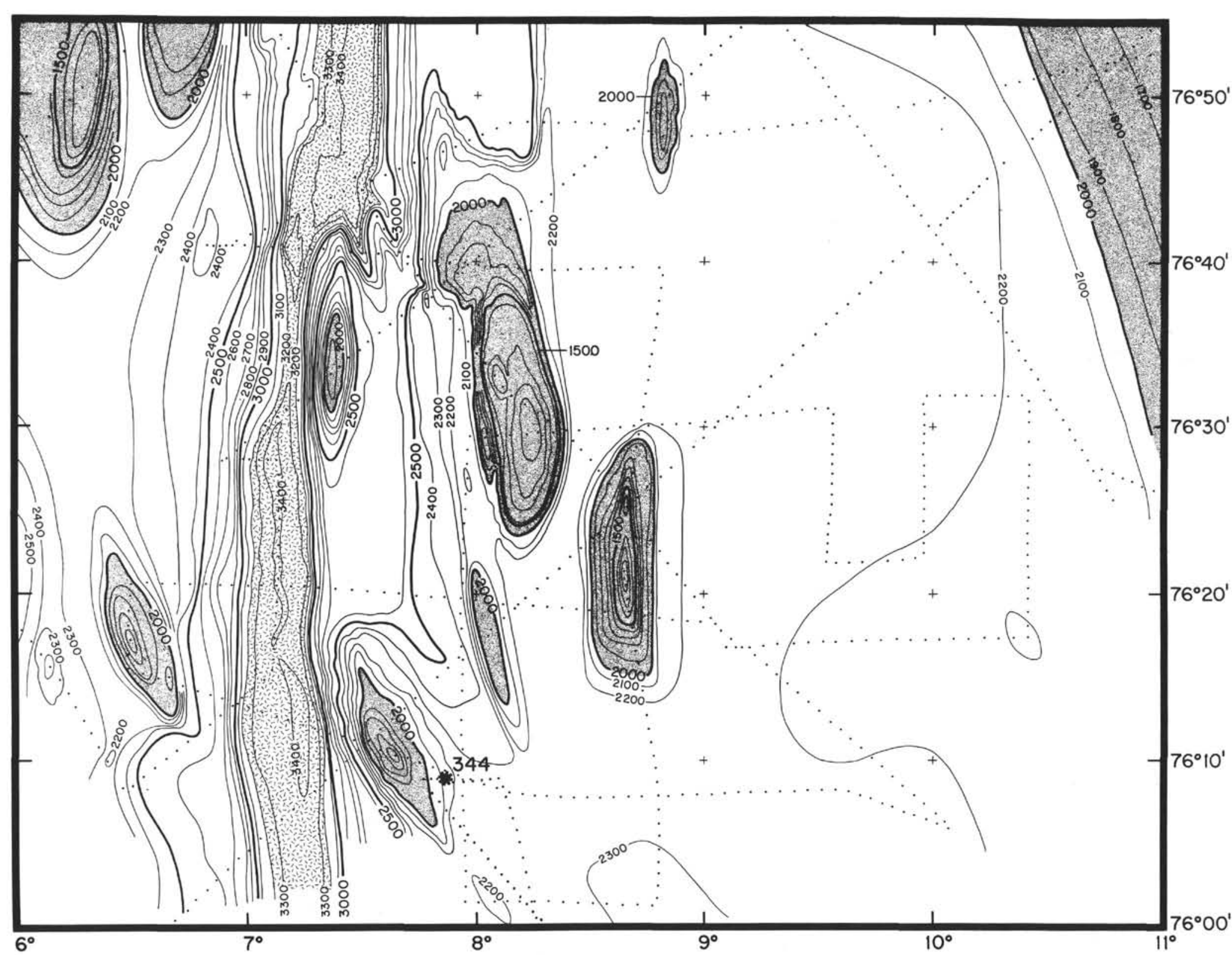

Figure 1. Bathymetric map near Site 344 east of the Knipovich Rift. The survey was made on Vema Cruise 30. The ship's track is shown by dots, contours are in corrected meters. Depths greater than 3200 meters and less than 2000 meters are indicated by shading. The contouring was done by Gleb Udintsev. 


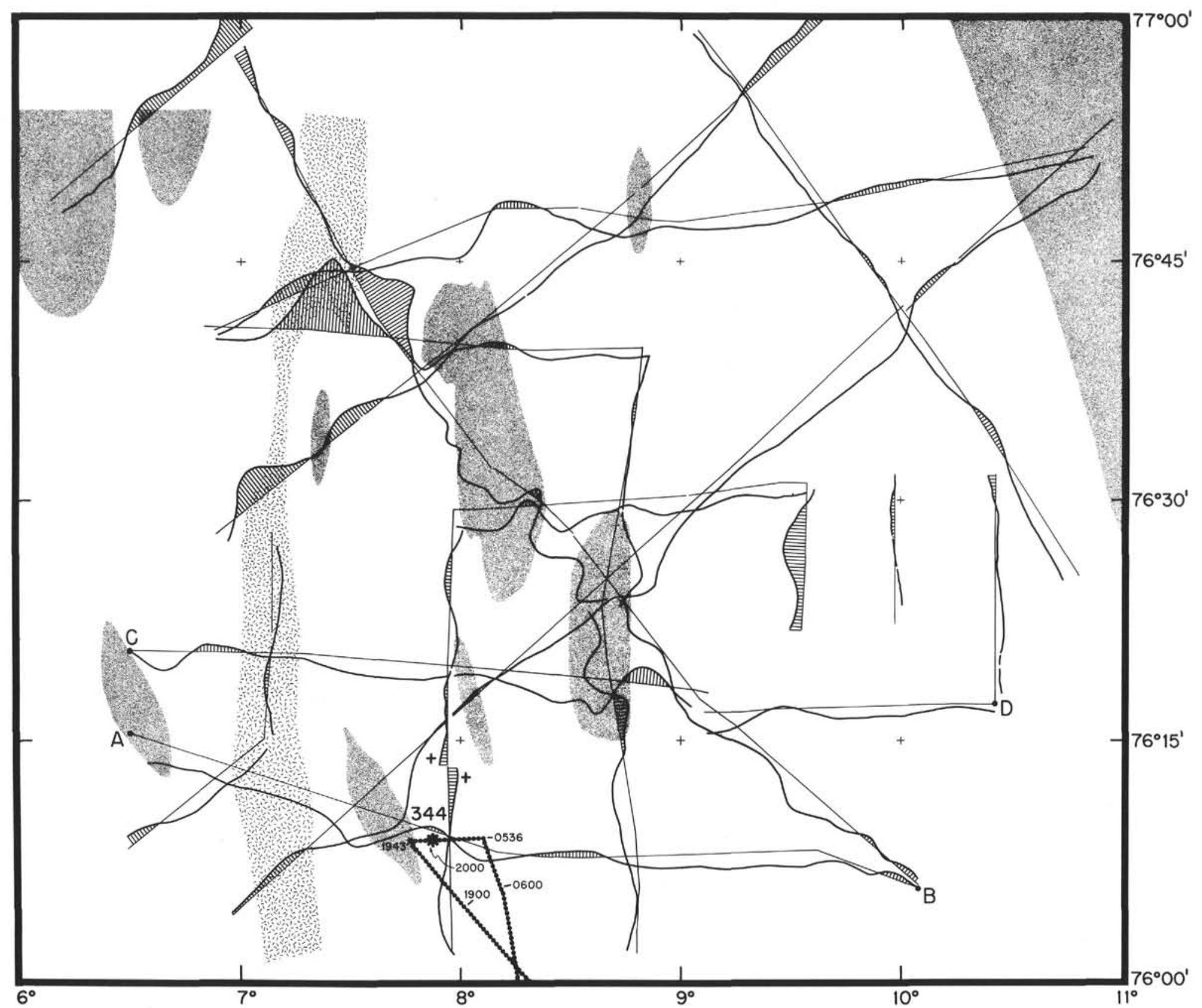

Figure 2. Magnetic anomalies plotted along Vema track near Site 344 east of the Knipovich Rift. Positive anomalies are indicated by rulings. Depths greater than 3200 meters and less than 2000 meters are indicated by shading as in Figure 1. 
M. TALWANI

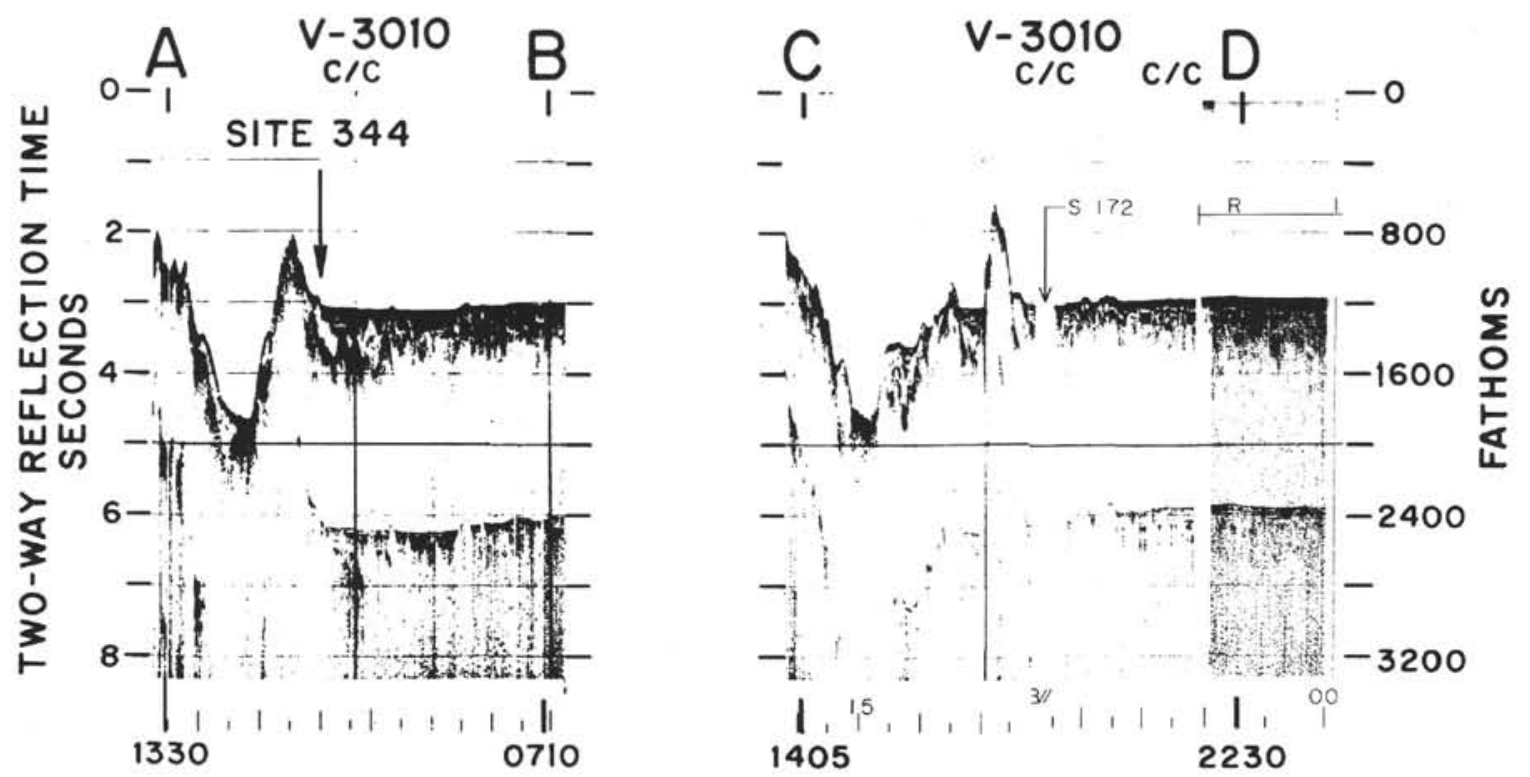

Figure 3. Vema single-channel seismic profiler records across the Knipovich Rift. The location of lines $A-B$ and $C-D$ is indicated in Figure 2. 